\title{
AQUISIÇÃO VERBAL E PROCESSAMENTO MORFOLÓGICO: UM ESTUDO PRELIMINAR*
}

\author{
ADQUISICIÓN VERBAL Y PROCESAMIENTO MORFOLÓGICO: UN ESTUDIO PRELIMINAR \\ VERBAL ACQUISITION AND MORPHOLOGICAL PROCESSING: A PRELIMINARY STUDY \\ Cristina Name** \\ Daniele de Souza Leite Molina*** \\ Universidade Federal de Juiz de Fora - UFJF, Juiz de Fora, BR
}

RESUMO: Investigamos a aquisição de um novo verbo e o tratamento morfológico de suas variações flexionais por crianças adquirindo o PB. Partimos da hipótese de que pistas distribucionais guiam o processo de reconhecimento de uma nova palavra como verbo. Além disso, a recorrência dos afixos verbais levaria à segmentação interna do verbo em raiz e afixos. Um experimento com a técnica de Fixação Preferencial do Olhar sugere que crianças de aproximadamente dois anos parecem adquirir o conceito de um novo verbo e tratar suas variações flexionais como palavras que compartilham um conceito base. Experimentos semelhantes com a técnica de Seleção de Imagem sugerem que crianças de três anos de idade mapeiam um conceito ao novo verbo, mas se mostram confusas quanto às variações flexionais. Já, aos quatro anos, demonstram adquirir tal conceito após uma curta fase de aprendizagem e tratar variações flexionais desse verbo como tendo o mesmo significado base.

PALAVRAS-CHAVE: aquisição da linguagem; verbos; processamento morfológico.

RESUMEN: Investigamos la adquisición de un nuevo verbo y el tratamiento morfológico de sus variaciones flexionales por niños adquiriendo el PB. Consideramos la hipótesis de que informaciones distribucionales conducen el proceso de reconocimiento de una nueva palabra como verbo. Además, la recurrencia de los afijos verbales conduce a la segmentación interna del verbo en raíz y afijos. Un experimento con la técnica de Fijación de la Mirada Preferencial sugiere que niños de dos años parecen adquirir el concepto de un nuevo verbo y tratar sus variaciones flexionales como palabras que comparten un concepto base. Experimentos semejantes con la técnica de Selección de Imagen sugieren que niños de tres años identifican el concepto del verbo, pero se quedan confusos con sus variaciones flexionales, mientras niños de cuatro años demuestran adquirir el concepto del verbo después de una corta fase de aprendizaje y tratar sus variaciones flexionales como compartiendo un significado base.

PALABRAS CLAVE: adquisición del lenguaje; verbos; procesamiento morfológico.

ABSTRACT: We investigate the acquisition of a novel verb and the morphological processing of its inflectional variations by children acquiring BP. We consider the hypothesis that distributional cues guide the recognition of a novel word as a verb. Besides, the recurrence of verbal affixes leads to the verb's internal segmentation into root and affixes. An experiment with the Split-Screen Preferential Looking Paradigm technique suggests two-year-old children seem to acquire the novel verb's concept and treat its inflectional variations as words that share a common meaning. Similar experiments with the Picture Identification Task technique suggest that three-year-old children tend to map a concept into the novel verb, but seem to be confused when tested with its inflectional variations. Four-year-old children, however, seem to acquire the concept of the novel verb after a brief familiarization and to treat its inflectional variations as sharing a basic meaning.

KEYWORDS: language acquisition; verbs; morphological processing.

\section{INTRODUÇÃO}

A aquisição de uma língua envolve uma série de capacidades perceptuais e cognitivas do bebê/da criança. No que se refere particularmente à aquisição lexical, fazem-se necessárias, dentre outras, habilidades de segmentação de palavras do fluxo contínuo da fala e de mapeamento dessas formas acústicas a seus conceitos. Ainda que algumas palavras mais salientes nos dados de fala dirigida à criança sejam rapidamente aprendidas (p.ex., pela sua frequência de ocorrência ou por pistas extralinguísticas presentes na cena comunicativa (cf. AKTAR; TOMASELLO, 2000)), a constituição de um léxico mental, i.e., a construção de representações lexicais, parece depender da delimitação de vocábulos no continuum da fala, do

\footnotetext{
* Trabalho desenvolvido no âmbito do projeto de pesquisa apoiado pelo CNPq (Processo no 401510/2010-7), aprovado pelo Comitê de Ética em Pesquisa/UFJF (Parecer $\mathrm{n}^{\circ}$ 100/2011). Este artigo é fruto da dissertação de mestrado, intitulada A aquisição verbal e o processamento morfológico por crianças adquirindo o PB, defendida em março de 2014.

** Professora Associada da Universidade Federal de Juiz de Fora; Coordenadora do NEALP/UFJF (Núcleo de Estudos em Aquisição da Linguagem e Psicolinguística); Bolsista de Produtividade em Pesquisa CNPq. E-mail: cristina.name@ufjf.edu.br.

**** Doutoranda pelo Programa de Pós-Graduação em Linguística da Faculdade de Letras da UFJF. E-mail: dani.molina@globo.com.
} 
reconhecimento de sua forma fonológica e de seu conteúdo semântico. Ainda, é preciso perceber que palavras são compostas por elementos menores providos de significado - os morfemas.

Pesquisas apontam para uma sensibilidade fina a diferenças acústicas entre segmentos vocálicos e consonantais durante os primeiros anos de vida do bebê, que vai se reduzindo a partir da exposição a uma língua. Entre seis e oito meses, o bebê passa a discriminar apenas as distinções vocálicas com valor fonêmico na língua, e em torno dos dez meses, processo semelhante ocorre em relação às consoantes (WERKER; TEES, 1984). Tal especialização é fundamental, já que palavras fonologicamente diferentes, geralmente, diferem quanto ao significado (ex.: bola vs. bala; lata vs. pata vs. mata etc.).

Porém, os processos morfológicos (derivacionais e, principalmente, flexionais) originam palavras fonologicamente diferentes que compartilham o mesmo significado base (ex.: garoto - garota - garotada; ando - anda - andou). Nesse sentido, a morfologia traz um conflito para a aquisição lexical, já que a criança deverá ser capaz de identificar que a distinção fonológica sinaliza uma distinção apenas parcial de sentido. Para isso, ela terá de segmentar internamente as palavras, reconhecendo a base comum - parte que preserva a mesma forma fonológica e o mesmo conceito - e afixos - que apresentam variação fonológica e de significado.

Estudos sugerem que bebês tratam, em uma etapa bastante inicial da aquisição do léxico, palavras que apresentam qualquer distinção fonológica como sendo palavras distintas (BORTFELD et al., 2005; WERKER et al., 2002). Jusczyk, Houston e Newsome (1999) verificaram que palavras relacionadas do inglês, tais como king e kingdom, são tratadas como palavras não relacionadas por bebês de 7.5 meses de idade, que não foram capazes de segmentar internamente as dissílabas. Em uma série de experimentos, Werker e colaboradores observaram, numa tarefa de aprendizagem de palavra (word-learning procedure), que crianças de 14 meses confundem, p.ex., bog e $\operatorname{dog}$ como uma mesma palavra, relacionando-as a um mesmo objeto. Crianças de 20 meses, por outro lado, tratam como palavras distintas, mapeando-as a objetos diferentes (ver WERKER; FENNELL, 2004 para revisão). Em conjunto, esses resultados revelam que as crianças considerariam, primeiramente, as palavras como um todo, sem perceber suas "partes"; distinções fonológicas, no início do segundo ano de vida, não remeteriam a conceitos diferentes. Ressalte-se, ainda, que a distinção fonológica tomada como distinção de significado diz respeito a par mínimo fonológico. Com base nesses resultados, não se pode falar de percepção de afixos.

No entanto, o reconhecimento de afixos - particularmente, de afixos flexionais - parece ser uma importante etapa na aquisição de uma língua pela criança. De acordo com a concepção minimalista de língua (CHOMSKY, 1995; 1999; 2001), a variação entre as línguas decorre da especificação dos traços formais de categorias funcionais. Traços de pessoa, número, tempo, aspecto e modo estariam especificados na morfologia flexional verbal, e caberia à criança/ao bebê identificá-los a partir da variação morfofonológica desses afixos (CORRÊA, 2007; 2009).

Categorias funcionais apresentam um número reduzido de elementos e resistem a alterações e à ampliação de seus conjuntos de itens. Em quaisquer língua e registro de fala naturais, os itens funcionais aparecem com muita frequência e apresentam características fônicas particulares, como a de serem menos proeminentes em sua forma acústica. Além disso, apresentam características distribucionais bastante específicas, ocorrendo em posições relativamente fixas (no início ou no fim da fronteira sintagmática) em relação a itens de categorias lexicais (CUTLER, 1993; SHI; MORGAN; ALLOPENNA, 1998; SHI; WERKER; CUTLER, 2006; CORREA, 2009).

Dessa forma, e com base na hipótese do bootstrapping prosódico (MORGAN; DEMUTH, 1996; CHRISTOPHE et al., 1997; 2008), os afixos verbais seriam precocemente percebidos pela frequência e sistematicidade com que aparecem no input. De acordo com essa hipótese, o bebê possui habilidades perceptuais precoces que lhe permitem fazer uma análise puramente fonológica do input e seria capaz de perceber padrões recorrentes no material linguístico a que está exposto. Em outras palavras, em uma fase inicial de aquisição da língua, a criança identificaria padrões que se mostram recorrentes na interface fônica (CORRÊA, 2007; 2009). Após segmentar as palavras do input, a criança analisaria a estrutura interna dos vocábulos, em especial nomes e verbos, reconhecendo bases, radicais e afixos por meio da recorrência desses elementos e de suas propriedades fônicas e distribucionais, que constituem padrões reconhecíveis na interface fônica. Em seguida, ocorreria o mapeamento dos significados e funções dos morfemas, permitindo seu uso em novas formações lexicais flexionadas e derivadas. 
Embora a aquisição verbal seja um tópico bastante estudado (GLEITMAN, 1990; FIGUEIRA, 2003; LOPES; SOUZA; ZILLI, 2005; BERNAL et al., 2007), são poucos os trabalhos focalizando aquisição de morfologia flexional verbal. Soderstrom (2002) observou que crianças de dezenove meses adquirindo o inglês apresentam preferência por sentenças que contenham flexão verbal se comparadas a sentenças sem nenhuma marcação flexional, indicando a sensibilidade das crianças a morfemas flexionais dos verbos. Shi e Cyr (2010) verificaram que, aos dois anos, crianças adquirindo o francês canadense atribuíram o mesmo conceito a variações morfológicas de um mesmo verbo, mas não distinguiram sufixos "reais" de inventados.

Inspiradas nesses trabalhos, investigamos a aquisição verbal e, particularmente, o processamento morfológico de sufixos verbais por crianças adquirindo o português brasileiro. Nossa hipótese é que a frequência e a sistematicidade dos morfemas flexionais verbais facilitariam (a) seu reconhecimento pela criança; (b) a identificação, por contraste, da forma base do verbo (raiz); e (c) a manutenção do mesmo significado base nas diferentes formas verbais.

Na próxima seção, trataremos da aquisição da morfologia verbal, considerando suas características no português, e apresentaremos o trabalho de Shi e Cyr (2010), que foi o ponto de partida deste estudo. Em seguida, apresentamos três experimentos realizados com crianças brasileiras de dois a quatro anos. Veremos que crianças nessa faixa etária parecem adquirir rapidamente o conceito de um novo verbo. No entanto, crianças de dois e três anos apresentam limitações quanto ao tratamento da variação flexional do novo verbo, comportamento distinto do verificado com crianças mais velhas (aos quatro anos de idade). Por fim, teceremos as considerações finais do trabalho, ponderando as contribuições deste estudo para a investigação da aquisição verbal.

\section{A AQUISIÇÃO DA MORFOLOGIA FLEXIONAL DE VERBOS}

Como já mencionado, a morfologia apresenta um “impasse” para a aquisição lexical, visto que, ao contrário do que ocorre nos casos em que uma alteração fonológica implica o reconhecimento de uma palavra diferente, não relacionada, as palavras que variam morfologicamente compartilham um significado base comum. Rosa (2006) destaca que, no par anda/andamos, há uma referência permanente - a que damos a "andar" -, mais a significação dos afixos, i.e., as referências de número/pessoa e de tempo/modo/aspecto. A autora ressalta os dois significados presentes nos verbos: o significado da base do verbo (morfema lexical ou raiz verbal) e o significado dos afixos verbais (morfemas gramaticais). Nos casos de verbos conjugados, portanto, o significado da forma verbal é estabelecido por meio do conceito permanente veiculado pela raiz verbal (unidade que concentra a significação básica do vocábulo) mais as noções gramaticais disponibilizadas pelos afixos verbais, princípio denominado de composicionalidade.

No caso do português, em que temos apenas sufixos flexionais (e não prefixos flexionais), a partir da detecção do final do verbo flexionado como um elemento funcional (ex.: andou; pulou; brincou etc.), a criança procederia à segmentação interna das formas verbais em raiz e afixos. Uma vez apreendidos os sufixos verbais como elementos de classe fechada e, portanto, sistemáticos na língua, a recorrência da raiz verbal também ajudaria a criança a identificar a parte que se mantém constante nas formas verbais flexionadas. Em outras palavras, ao ouvir um mesmo verbo flexionado em número/pessoa e tempo/modo verbais distintos (ex.: andou; andamos; andando etc.), a criança identifica uma forma fônica constante - a raiz verbal -, bem como é sensível à recorrência dos sufixos flexionais verbais presentes na língua, fazendo, assim, a segmentação interna dos verbos flexionados.

Shi e Cyr (2010) investigaram se crianças entre 20 e 25 meses de vida, adquirindo o francês canadense, mapeiam uma ação a um novo verbo. Além disso, buscaram investigar como elas interpretam variações flexionais de uma nova forma verbal. A atividade experimental desenvolvida pelas pesquisadoras constava de sentenças com o pseudoverbo brécher: utilizou-se o morfema verbal /e/ (altamente frequente e regular na língua francesa), formando o passado "a bréché" (/bréšé/) ${ }^{1}$; sua variante morfológica de presente "brèche" (/brĚš/), semelhante às formas verbais francesas / repete/-/repct/; e com sufixo raro no francês "bréchit"

\footnotetext{
${ }^{1}$ Em francês, o passado é composto - nesse caso, pelo verbo avoir (ter) no presente - e o particípio passado do verbo principal.

${ }^{2} \mathrm{O}$ sufixo -i não é mais usado no francês falado. Seu uso restringe-se à escrita, geralmente, a textos literários, referindo-se à forma de passado simples. Não sabemos, no entanto, se esse afixo verbal aparece, por exemplo, em livros de estória infantil, podendo ser familiar para as crianças. As autoras não discutem a escolha desse morfema, que é apresentado por elas, na verdade, como um não morfema do francês.
} 
(/breši/). Cabe ressaltar que as formas "bréché" e "brèche" apresentam uma mudança fonética (br/e/che $\mathrm{br} / \varepsilon / \mathrm{che})$, porém são morfologicamente relacionadas, ao passo que "bréché" e "bréchit" formam um par mínimo, sendo, por outro lado, relacionados fonologicamente, mas não morfologicamente. Os enunciados eram acompanhados de pequenos vídeos em que se apresentava um peixinho realizando uma ação.

Os resultados sugerem o início de um conhecimento morfológico, isto é, um conhecimento emergente, porém limitado, uma vez que a maioria das crianças não interpretou "bréché" e "brèche" como tendo o mesmo significado. Por outro lado, há evidências de que as crianças tratam os morfemas e não a semelhança fonológica das formas verbais, visto que, embora fonologicamente muito parecidos (formando um par mínimo) as formas "bréché" e "bréchit" não foram tratadas como itens lexicais relacionados.

Diante dos resultados encontrados por Shi e Cyr (2010) com crianças de dois anos adquirindo o francês canadense, buscamos verificar se crianças nessa idade adquirindo o PB são capazes de perceber o significado permanente da raiz verbal em diferentes ocorrências de um novo verbo. Além disso, partindo da hipótese de que a apreensão do paradigma verbal da língua ocorre por meio do reconhecimento da recorrência dos afixos verbais, investigamos se uma forma meramente relacionada fonologicamente (mas não morfologicamente) seria tomada como variação flexional dessa forma verbal. Para isso, o novo verbo foi adjungido a um "não afixo" (pseudoafixo que não pertence ao paradigma verbal do português).

\section{ATIVIDADES EXPERIMENTAIS}

Tendo como objetivos investigar: (1) a aquisição de um novo verbo e o reconhecimento do conceito base do verbo disponibilizado pela raiz verbal, apesar das variações morfológicas presentes nos afixos, e (2) a identificação de sufixos verbais do português (em oposição a um não sufixo), foram realizadas três atividades experimentais. $\mathrm{O}$ primeiro experimento foi realizado com crianças de dois anos, usando-se a técnica de Fixação Preferencial de Olhar. O segundo e o terceiro experimentos testaram crianças de três e quatro anos, respectivamente, ambos com a técnica de Seleção de Imagem.

\subsection{Experimento 1}

\subsubsection{Método}

Participantes: Participaram deste experimento doze crianças entre 18 e 33 meses de idade (1;6 a 2;9 ano(s) de vida), dando uma média de idade de 25,5 meses. Das doze crianças testadas, quatro foram eliminadas: por inquietação (1), por apatia (1) e por choro (2). Portanto, os resultados encontrados são referentes a oito crianças, dentre as quais cinco são meninas e três são meninos, que foram divididas em dois grupos. De acordo com os responsáveis, as crianças não apresentam histórico familiar de queixas de linguagem e são filhos de pais brasileiros monolíngues.

Material: Foram apresentados às crianças estímulos visuais e auditivos, linguísticos. Os estímulos visuais consistiam de quatro vídeos curtos: um peixinho nadando para dentro de uma bolha (vídeo A), um peixinho passando por cima de uma bolha (vídeo B), um peixinho nadando, batendo na bolha e voltando sem entrar (vídeo C) e um peixinho subindo e descendo em seguida sem conseguir passar por cima da bolha (vídeo D). Em todos os vídeos, peixinho, bolha e fundo eram sempre os mesmos.

Foi criado um pseudoverbo - mepar -, apresentado na $3^{\text {a }}$. pessoa do singular no passado (mepou) e no presente (mepa). Além disso, o pseudoverbo foi apresentado com um "não afixo" verbal (mepê), com o objetivo de contrastar formas relacionadas morfologicamente com formas apenas fonologicamente relacionadas. Chegou-se à escolha do "não afixo" -ê, após se verificar que, na primeira conjugação verbal, não há, no paradigma flexional do português, formas verbais arrizotônicas terminadas em -e. Enunciados contendo as variações de mepar foram criados, gravados previamente por uma falante nativa do PB. Para apresentar e fixar o conceito de mepar, os enunciados "Olha! Ele mepou?" e "Olha! Ele não mepou?" acompanharam os vídeos A e C para um grupo de crianças e B e D para outro grupo. Para verificar a apreensão do significado verbal e o reconhecimento ou não do sufixo, foram apresentados os enunciados "Olha! Ele mepa" (condição congruente) e "Olha! Ele mepê! (condição incongruente). A produção dos estímulos linguísticos foi a mais natural possível, sem enfatizar os afixos verbais. 
Design: O experimento consistiu de uma fase de aprendizagem e de uma fase de teste. Na fase de aprendizagem, era apresentada à criança, no centro de uma tela, a animação de um peixinho nadando para dentro de uma bolha (vídeo A, grupo 1) ou de um peixinho passando por cima da bolha (vídeo B, grupo 2). Juntamente com a animação (mas só depois de o peixinho concluir a ação, ou seja, depois de ele entrar na bolha ou de passar completamente pela bolha), a criança ouvia "Olha! Ele mepou!". Tomou-se cuidado com o momento em que era produzido o estímulo linguístico para que ficasse compatível com a noção temporal do afixo. Essa cena (vídeo + áudio) se repetia mais uma vez. O objetivo dessa fase era mostrar para a criança o conceito do verbo mepar. Da mesma forma, apresentava-se à criança a animação do peixinho nadando e batendo na bolha, ou seja, não conseguindo entrar na bolha (vídeo C, grupo 1). Com essa animação, falavase para criança "Olha! Ele não mepou!". Para o grupo 2, a animação era do peixinho subindo para passar pela bolha, mas descendo logo em seguida, ou seja, como se também não conseguisse "mepar" (vídeo C). Essa cena (vídeo + áudio) também era apresentada duas vezes com o estímulo "Olha! Ele não mepou!", com o objetivo de consolidar o conceito de mepar. Os dois tipos de ensaios eram repetidos por uma segunda vez.

Já na fase de teste, as duas animações (nadar para dentro da bolha e nadar passando por cima da bolha) eram apresentadas simultaneamente na tela, que era dividida ao meio. Essa fase era constituída de quatro ensaios. O primeiro e o último foram usados como baselines, com a repetição das cenas de mepou e não mepou, respectivamente, para a verificação da aquisição do conceito do novo verbo pela criança. No segundo e no terceiro ensaios, os vídeos eram acompanhados dos estímulos com mepa e mepê. Vale ressaltar que a animação foi adaptada: o peixinho praticava a ação duas vezes e mais rapidamente, e só depois o áudio era produzido. Utilizamos o presente do indicativo em um contex to que indicasse uma habilidade do peixinho, já que não é comum no PB o uso do presente do indicativo para a descrição de uma ação/um evento que esteja em curso no momento da fala (para esse caso seria mais comum, no PB, o uso do presente contínuo). As figuras a seguir mostram como as animações eram apresentadas na fase de aprendizagem e na fase de teste, respectivamente:

Figura 1- Fase de aprendizagem

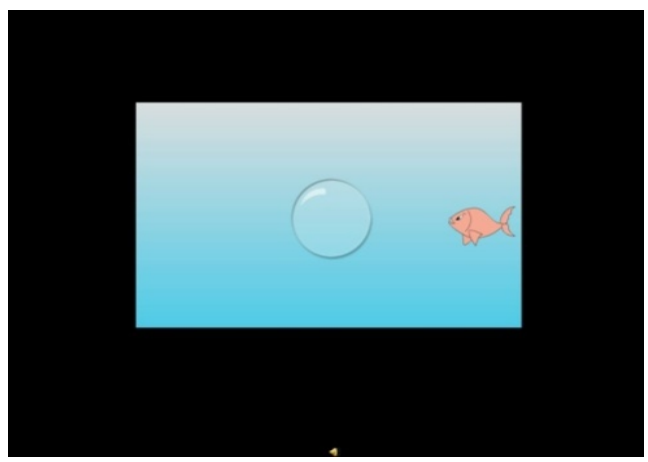

Figura 2 - Fase de teste

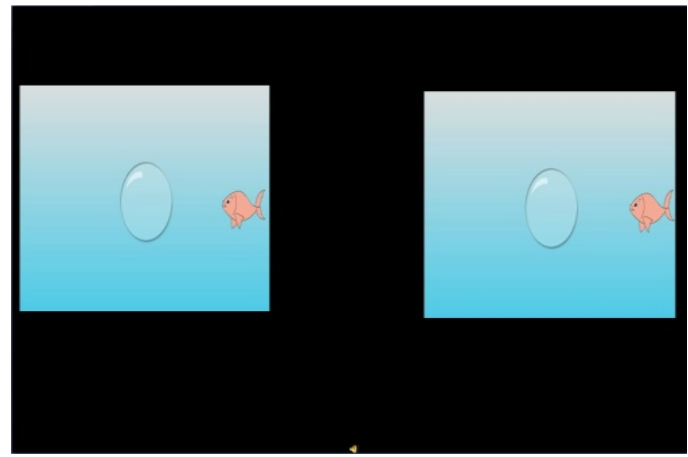

Foi tomada como variável independente a propriedade morfológica das variações do pseudoverbo - tipo de sufixo verbal, tendo dois níveis de manifestação: afixo existente e regular na língua (morfema de presente do modo indicativo) e afixo inexistente na língua (um não morfema). Como variável dependente, considerou-se o tempo de fixação do olhar, em segundos.

Procedimento: Os participantes foram testados individualmente no laboratório do NEALP, com a técnica da Fixação Preferencial do Olhar (Split-Screen Preferential Looking Paradigm). Nessa técnica, há a utilização conjunta de estímulos visuais - animações - e de estímulos auditivos - enunciados linguísticos. Tal técnica requer a utilização de duas telas (televisões ou monitores) ou, alternativamente, um televisor grande cuja tela encontre-se dividida em duas partes (essa segunda opção foi a utilizada em nosso experimento). Além disso, são necessários um alto-falante, uma câmera de vídeo e um computador.

Ao chegar ao laboratório com a criança, o responsável era informado sobre a pesquisa e o desenvolvimento da atividade. Enquanto isso, a criança era incentivada a brincar com brinquedos colocados em tapete emborrachado, de modo a se familiarizar com o ambiente. Em seguida, a criança e o responsável eram convidados a passar para outro ambiente, no qual aconteceria o experimento. O responsável se sentava em uma cadeira confortável com a criança em seu colo, tendo à frente, centralizada, uma tela de televisão em cima de uma mesa. Atrás da tela, escondida da criança, a experimentadora controlava a apresentação dos 
estímulos. O responsável foi orientado a não interferir no comportamento da criança, evitando apontar para a tela ou falar com a criança durante toda a atividade.

O experimento iniciava-se com a tela preta. Em seguida, os slides eram passados um a um. Inicialmente, mostravam-se à criança algumas imagens infantis com a frase "Olha!" (por exemplo, os desenhos de um balão e de uma casa). Optou-se por iniciar a atividade dessa forma para que a criança se acostumasse com a atividade. Logo após essas figuras, começava-se efetivamente o experimento, com a apresentação das animações da fase de aprendizagem, que durava até dois minutos. Em seguida, iniciava-se a fase de teste, na qual duas animações apareciam simultaneamente. Como já foi visto, quatro ensaios eram apresentados, sendo o primeiro e o quarto usados como baselines para a verificação da aquisição do conceito do novo verbo pela criança, e o segundo e o terceiro usados para testar o reconhecimento (ou não) de sufixo verbal/não sufixo pela criança. A ordem de apresentação dos estímulos mepa e mepê nesses ensaios foi contrabalanceada entre os participantes. A posição em que apareciam as animações entre os lados direito e esquerdo da tela também foi aleatorizada. Para encerrar, ao final dos quatro ensaios de teste, mostrava-se uma figura com o áudio "Olha!", como feito no início da atividade. Toda a seção experimental foi gravada para posterior análise.

Os vídeos do rosto das crianças foram posteriormente analisados no programa Supercoder (HOLLICH, 2008). Mensurou-se o tempo de fixação do olhar ${ }^{3}$ para a tela correspondente ao enunciado linguístico, podendo corresponder a um tempo cumulativo de olhar para uma determinada tela. Nossa previsão era que, se a criança fosse capaz de perceber o significado permanente da raiz verbal em diferentes ocorrências do novo verbo, olharia mais tempo, na condição mepa, para a imagem semelhante à da familiarização. Ainda, se a criança rejeitasse a forma com o não sufixo (relacionada fonologicamente, mas não morfologicamente), esperava-se maior tempo de fixação na imagem contrária à da familiarização na condição mepê.

\subsubsection{Resultados e discussão}

Os resultados foram obtidos a partir da filmagem feita dos rostos das crianças durante a seção experimental. Utilizamos o programa Supercoder $(\mathrm{HOLLICH}, 2008)$ para rodar os vídeos e proceder à marcação do tempo para um lado ou outro da tela. A marcação do tempo de olhar para o lado direito e para o lado esquerdo, durante a fase de teste, foi feita às cegas, ou seja, sem o conhecimento de qual lado correspondia à animação-alvo (àquela mostrada na fase de aprendizagem), evitando-se, assim, qualquer interferência, mesmo que não proposital, na codagem dos tempos de olhar. A verificação do lado em que estava a animação-alvo foi feita após a marcação temporal. O tempo obtido em cada ensaio corresponde ao tempo cumulativo de olhar para cada lado da tela. Foi calculado, ainda, o percentual de olhar - a proporção de tempo de fixação de olhar - para a animação-alvo em relação ao tempo total de olhar para as animações. Em consonância com a análise de Shi e Cyr (2010), considerou-se, como resultado positivo, uma proporção acima de $0.5(50 \%)$ do tempo de olhar para o evento-alvo, sendo nulo um resultado no nível da chance, isto é, tempo de olhar proporcionalmente igual para as duas animações apresentadas simultaneamente. Também foram realizadas comparações dos resultados entre as condições. Os dados correspondentes ao estímulo de teste "Ele mepou" estão descritos na tabela 1, abaixo.

Observa-se, a partir dos dados expostos na tabela 1, que das oito crianças testadas, se tomadas como um único grupo, cinco delas tiveram um maior tempo de olhar para a mesma ação mostrada na fase de aprendizagem se comparado ao tempo de olhar para a ação oposta (evento "novo"). Duas olharam por mais tempo para a ação diferente da apresentada na fase de aprendizagem e uma das crianças não apresentou diferença no tempo de fixação do olhar. Esse resultado sugere que a maioria das crianças (5 de 8) mapeou o novo verbo à ação mostrada na curta fase de aprendizagem.

O cálculo das médias do tempo de olhar para a mesma ação apresentada na fase de aprendizagem e para a ação nova revela um tempo de fixação do olhar um pouco maior para a mesma ação, considerando o grupo de crianças testadas, que, em média, olhou $54 \%$ do total do tempo de olhar para a animação-alvo.

\footnotetext{
${ }^{3}$ Consideramos que a mensuração do tempo de olhar seja feita pelo software em segundos, no entanto, não obtivemos uma confirmação da medida de tempo utilizada pelo programa. Deve-se ressaltar que, de qualquer forma, o tempo de fixação foi medido utilizando-se a mesma unidade de tempo para todos os participantes.
} 
Tabela 1 - Tempo de fixação do olhar por participante (mepou)

\begin{tabular}{|c|c|c|c|c|c|}
\hline \multicolumn{6}{|l|}{ MEPOU } \\
\hline Criança & Idade & Mesma ação & Ação diferente & Total $\mathrm{LT}^{4}$ & $\%^{5}$ \\
\hline A & $1 ; 6$ & 116 & 117 & 233 & 49 \\
\hline B & $1 ; 7$ & 100 & 123 & 223 & 44 \\
\hline $\mathrm{C}$ & $1 ; 10$ & 98 & 30 & 128 & 76 \\
\hline $\mathrm{D}$ & $1 ; 10$ & 108 & 86 & 194 & 55 \\
\hline $\mathrm{E}$ & $2 ; 3$ & 110 & 62 & 172 & 63 \\
\hline $\mathrm{F}$ & $2 ; 8$ & 126 & 73 & 199 & 63 \\
\hline G & $2 ; 8$ & 38 & 77 & 115 & 33 \\
\hline $\mathrm{H}$ & $2 ; 9$ & 95 & 85 & 180 & 52 \\
\hline Média total & $2 ; 1$ & 98,875 & 81,625 & 180,5 & 54 \\
\hline Média & & & & & \\
\hline$<2$ anos & $1 ; 7$ & 105,5 & 89 & 194,5 & 54 \\
\hline Média & & & & & \\
\hline$>2$ anos & $2 ; 6$ & 92,25 & 74,25 & 166,5 & 55 \\
\hline
\end{tabular}

Ressaltamos que, nesse ensaio, diferentemente do experimento canadense, as crianças assistiram a uma animação já conhecida e a uma nova animação, não apresentada anteriormente. Dessa forma, a novidade da ação não apresentada na fase de aprendizagem pode ter atraído a atenção das crianças, levando a um tempo de olhar bastante alto também para a ação nova, já que era a primeira vez que a animação estava sendo mostrada. Ainda assim, houve uma ligeira preferência pela imagem-alvo, em termos gerais.

Deve-se levar em consideração, no entanto, a grande faixa etária considerada. O experimento feito com crianças adquirindo o francês canadense testou crianças entre 20 e 25 meses e não obteve resultados significativos (cf. SHI; CYR, 2010). As próprias autoras levantaram a possibilidade de os resultados encontrados serem decorrentes da faixa etária. Analisamos, portanto, se haveria diferenças comportamentais entre as crianças mais velhas e as mais novas dentro do grupo testado. Vale destacar que quatro crianças tinham mais de dois anos de idade e quatro estavam abaixo dos dois anos. Observamos que três das crianças com mais de dois anos de idade olharam por mais tempo para a animação vista na fase de aprendizagem. Já dentre as crianças abaixo dos dois anos de idade, apenas duas crianças olharam por mais tempo para a animação-alvo, enquanto outra apresentou maior tempo de olhar para a ação nova e uma não apresentou diferença no tempo de olhar para uma ou outra animação.

Mas quando comparamos o percentual do tempo de olhar para a animação-alvo com o tempo total de olhar para a tela durante o ensaio "mepou", não há diferença entre os grupos etários, visto que as crianças com

\footnotetext{
${ }^{4}$ LT, do inglês Looking Time (Tempo (total) do Olhar).

${ }^{5}$ Percentual do tempo de olhar para a animação-alvo, calculado a partir do tempo total de olhar para as animações.
} 
idades abaixo dos dois anos olharam $54 \%$ do tempo total para a animação-alvo e as crianças acima dos dois anos olharam $55 \%$ do tempo total para a animação-alvo.

A tabela seguinte apresenta os tempos de fixação do olhar para cada animação por participante no ensaio que testou o tratamento da variação morfológica desse novo verbo - mepa.

Tabela 2 - Tempo de fixação do olhar por participante (mepa)

\begin{tabular}{|c|c|c|c|c|c|}
\hline \multicolumn{6}{|l|}{ MEPA } \\
\hline Criança & Idade & Mesma ação & Ação diferente & Total LT & $\%$ \\
\hline A & $1 ; 6$ & 60 & 75 & 135 & 44 \\
\hline B & $1 ; 7$ & 80 & 166 & 246 & 32 \\
\hline $\mathrm{C}$ & $1 ; 10$ & 8 & 49 & 57 & 14 \\
\hline $\mathrm{D}$ & $1 ; 10$ & 27 & 46 & 73 & 36 \\
\hline $\mathrm{E}$ & $2 ; 3$ & 54 & 29 & 83 & 65 \\
\hline $\mathrm{F}$ & $2 ; 8$ & 23 & 91 & 114 & 20 \\
\hline G & $2 ; 8$ & 69 & 29 & 98 & 70 \\
\hline $\mathrm{H}$ & $2 ; 9$ & 142 & 36 & 178 & 79 \\
\hline $\begin{array}{l}\text { Média } \\
\text { total }\end{array}$ & $2 ; 1$ & 57,875 & 65,125 & 123 & 47 \\
\hline Média & & & & & \\
\hline$<2$ anos & $1 ; 7$ & 43,75 & 84 & 127,75 & 34 \\
\hline Média & & & & & \\
\hline$>2$ anos & $2 ; 6$ & 72 & 46,25 & 118,25 & 60 \\
\hline
\end{tabular}

Em relação ao ensaio "mepa", temos que todas as crianças que olharam por mais tempo para a animação do peixinho praticando a mesma ação de mepou tinham acima de dois anos de vida (três crianças das quatro acima dos dois anos olharam por mais tempo para a ação mapeada como mepou). As crianças com idade abaixo dos dois anos parecem não tratar mepa como variação de mepou, já que todas as quatro crianças olharam por mais tempo para o novo evento.

Quando verificamos o tempo de olhar para a animação-alvo (a correspondente à ação de "mepar"), temos uma diferença comportamental se consideramos os dois grupos etários. As crianças acima dos dois anos de idade apresentaram um tempo médio de olhar de $60 \%$ de todo o tempo de reação para a animação-alvo, enquanto que as crianças com idades abaixo dos dois anos apresentaram apenas $34 \%$ do tempo de reação para a mesma animação (em média). Portanto, os resultados apontam para um mapeamento da forma mepa à ação semelhante à apresentada como mepou durante a fase de aprendizagem pelas crianças mais velhas.

Com relação ao estímulo "mepê", vale relembrar que estabelecemos como previsão que, não havendo o reconhecimento de um sufixo verbal frequente do português, as crianças não tratariam essa pseudoforma como uma variação de "mepou”. Os dados acerca do tempo de olhar por participante e as comparações entre o tempo de olhar para a animação-alvo e o tempo total de olhar ao ouvirem o ensaio "mepể estão descritos na tabela abaixo: 
Tabela 3 - Tempo de fixação do olhar por participante (mepê)

\begin{tabular}{|c|c|c|c|c|c|}
\hline \multicolumn{6}{|l|}{ MEPE } \\
\hline Criança & Idade & Mesma ação & Ação diferente & Total LT & $\%$ \\
\hline $\mathrm{A}$ & $1 ; 6$ & 70 & 92 & 162 & 43 \\
\hline $\mathrm{B}$ & $1 ; 7$ & 50 & 110 & 160 & 31 \\
\hline $\mathrm{C}$ & $1 ; 10$ & 17 & 56 & 73 & 23 \\
\hline $\mathrm{D}$ & $1 ; 10$ & 47 & 63 & 110 & 42 \\
\hline $\mathrm{E}$ & $2 ; 3$ & 97 & 64 & 161 & 60 \\
\hline $\mathrm{F}$ & $2 ; 8$ & 195 & 28 & 223 & 87 \\
\hline G & $2 ; 8$ & o & 31 & 31 & 0 \\
\hline $\mathrm{H}$ & $2 ; 9$ & 133 & 104 & 237 & 56 \\
\hline \multicolumn{6}{|l|}{ Média } \\
\hline \multicolumn{6}{|l|}{ Média } \\
\hline$<2$ anos & $1 ; 7$ & 46 & 80,25 & 126,25 & 36 \\
\hline \multicolumn{6}{|l|}{ Média } \\
\hline$>2$ anos & $2 ; 6$ & 106,25 & 56,75 & 163 & 65 \\
\hline
\end{tabular}

Quando ouviram o estímulo "Ele mepể, três das quatro crianças com idades acima dos dois anos olharam por mais tempo para a mesma ação mapeada como mepou. Quando analisada a proporção do tempo de olhar para a animação-alvo comparada ao tempo total de olhar para esse ensaio, temos que as crianças acima dos dois anos de idade olharam $65 \%$ para a animação familiarizada, enquanto que as crianças abaixo dessa faixa etária olharam apenas $36 \%$ para a mesma ação mostrada na fase de aprendizagem. Tal resultado é semelhante aos encontrados na faixa dos quatro anos de idade, ou seja, mesmo que a criança não reconheça - $\hat{e}$ como morfema verbal do português, pode ser uma estratégia a de mapear essa forma fônica desconhecida a algo já conhecido. Destacamos que a recorrência da raiz verbal (mep-) pode influenciar tal comportamento. Além disso, este experimento foi elaborado de forma bastante próxima do feito no francês canadense para possibilitar a comparação dos resultados. Vale destacar, portanto, que não houve estímulos distratores, isto é, os estímulos mepou, mepa e mepê eram ouvidos em sequência, o que pode ter evidenciado a recorrência da raiz. Por outro lado, das crianças com idade abaixo dos dois anos, todas as quatro olharam por mais tempo para a ação diferente, apontando para o não mapeamento de variações flexionais de uma mesma palavra como tendo um significado base comum.

Vale ressaltar que, nos ensaios intermediários, isto é, mepa e mepê, é possível que a animação nova tenha ficado um tanto familiar para o participante, de modo que a novidade já não influenciaria a reação da criança. Assim, a preferência pela mesma animação mostrada na fase de aprendizagem e mapeada como mepou parece mais evidente nesses ensaios.

Por fim, analisamos os dados obtidos com o estímulo "não mepou", apresentados abaixo, na tabela 4.

Para o ensaio "não mepoü, estabelecemos que os participantes olhariam por mais tempo para a animação mostrada na fase de aprendizagem com o estímulo "Ele não mepou", visto que, para consolidar o conceito de 
mepar, foram apresentadas previamente animações do peixinho "não conseguindo mepar" (ou como o peixinho batendo na bolha e não conseguindo entrar (grupo 1), ou como o peixinho subindo para passar pela bolha mas não completando a ação (grupo 2)).

Tabela 4 - Tempo de fixação do olhar por participante (não mepou)

\begin{tabular}{|c|c|c|c|c|c|}
\hline \multicolumn{6}{|c|}{ NÃO MEPOU } \\
\hline Criança & Idade & Mesma ação & Ação diferente & Total RT & $\%$ \\
\hline A & $1 ; 6$ & 41 & 35 & 76 & 53 \\
\hline B & $1 ; 7$ & 64 & 46 & 110 & 58 \\
\hline $\mathrm{C}$ & $1 ; 10$ & 70 & 62 & 132 & 53 \\
\hline $\mathrm{D}$ & $1 ; 10$ & 85 & 101 & 186 & 45 \\
\hline $\mathrm{E}$ & $2 ; 3$ & 97 & 49 & 146 & 66 \\
\hline $\mathrm{F}$ & $2 ; 8$ & 18 & 55 & 73 & 24 \\
\hline G & $2 ; 8$ & 62 & 8 & 70 & 88 \\
\hline $\mathrm{H}$ & $2 ; 9$ & 104 & 90 & 194 & 53 \\
\hline \multicolumn{6}{|l|}{ Média } \\
\hline \multicolumn{6}{|l|}{ Média } \\
\hline$<2$ anos & $1 ; 7$ & 65 & 61 & 126 & 51 \\
\hline \multicolumn{6}{|l|}{ Média } \\
\hline$>2$ anos & $2 ; 6$ & 70,25 & 50,5 & 120,75 & 58 \\
\hline
\end{tabular}

Os dados nos mostram que seis crianças das oito testadas olharam por mais tempo para a animação mostrada com este estímulo na fase de aprendizagem, sendo três da faixa etária acima dos dois anos e três da faixa abaixo dos dois anos. As crianças atentaram para a mesma animação ao ouvirem o mesmo estímulo da fase de aprendizagem, indicando que o conceito do novo verbo foi adquirido. Além disso, podemos dizer que os dados mostram-se ainda mais evidentes, no que diz respeito à confirmação de aquisição do conceito de mepar, para as crianças acima dos dois anos de idade, já que elas olharam $58 \%$ do tempo total de reação para a animação-alvo, enquanto que as crianças mais novas (abaixo dos dois anos de idade) dispensaram $51 \%$ do tempo total de reação para a mesma ação mostrada na fase de aprendizagem como mepou.

Retomando, portanto, a análise descritiva apresentada acima, temos que, na fase de teste, ao ouvirem "Ele mepou", os participantes demonstraram uma ligeira preferência pela mesma ação apresentada na fase de aprendizagem, sugerindo a aquisição do conceito base do novo verbo ("mepar"). Ressaltamos, contudo, que, ao compararmos a ação familiarizada com uma ação nova (ainda não apresentada durante a atividade), o fator novidade pode ter chamado demasiada atenção do participante, fazendo com que o tempo de olhar fosse alto para ambas as animações. Ainda assim, a preferência pela animação mostrada como mepou ficou acima do nível da chance. Já no estímulo "mepa", a animação nova já não seria novidade (a novidade já teria sido amenizada), de modo que, ao ouvirem "Ele $m e p a$ ", as crianças com idade acima dos dois anos preferiram a mesma animação mapeada como mepou. 
Esses dados sugerem que as formas mерои e тера foram mapeadas a um mesmo conceito base. Vale destacar que o mesmo comportamento não foi identificado nas crianças com idade abaixo dos dois anos. De forma semelhante, houve preferência pela mesma ação mapeada como "mepou", quando as crianças acima dos dois anos de idade ouviram "Ele mepê", sugerindo que as crianças dessa faixa etária assumem as formas mepou, mepa e mepê como tendo a mesma base lexical. Por fim, o ensaio "Ele não mepoü" corrobora os resultados encontrados com "Ele mepou", já que houve preferência pela mesma ação mostrada na fase de aprendizagem.

A análise estatística (teste-t) da proporção de tempo médio de fixação do olhar para a animação-alvo comparada ao nível de chance (0.5) para cada condição (cf. SHI; CYR, 2010) não revelou valor significativo de $p$, como já podíamos imaginar com base na análise descritiva dos dados (mepou: $\mathrm{M}=0.54, \mathrm{t}(7)=0.94, \mathrm{p}<$ 0.1; тера: $\mathrm{M}=0.45, \mathrm{t}(7)=0.6, \mathrm{p}=0.28 ;$ mepê: $\mathrm{M}=0.43, \mathrm{t}(7)=0.78, \mathrm{p}=0.23$; não meроu: $\mathrm{M}=0.55, \mathrm{t}(7)=$ $0.78, \mathrm{p}=0.23)$. O número reduzido de crianças, assim como a variação alta de média de LT em alguns casos (p.ex., no ensaio de teste de mepou, um participante apresentou tempo total de olhar de 233, enquanto outro de 115), provavelmente contribuíram para a não significância. Além disso, a amostra limitada a quatro crianças em cada grupo etário impossibilita a análise estatística por grupo, fator que parece ter tido efeito sobre o tempo de fixação do olhar (variável dependente), de acordo com a análise descritiva. Para a análise comparativa dos tempos de fixação de olhar entre as condições, foi conduzida one-way ANOVA de medidas repetidas, que também não revelou diferença significativa: $\mathrm{f}(1,7)=0.59, \mathrm{p}=0.5$. Novamente, esses resultados não são surpreendentes se considerada a análise descritiva feita anteriormente.

Os resultados encontrados no experimento com crianças na faixa de dois anos adquirindo o $\mathrm{PB}$, ainda que inconclusivos, apontam para uma capacidade progressiva da criança em mapear formas morfologicamente relacionadas a um mesmo conceito base, mas sugerem que, nessa idade, as crianças ainda não distinguem sufixos verbais do português e não sufixos. A fim de verificar se crianças mais velhas seriam capazes de tal distinção, realizamos um experimento semelhante com crianças de três anos, com a técnica de Seleção de Imagem ${ }^{6}$.

\subsection{Experimento 2}

\subsubsection{Método}

Participantes: Participaram dessa atividade experimental 16 crianças de aproximadamente três anos de idade $^{7}$, sendo nove meninas e sete meninos.

Material: O mesmo material preparado para o experimento com crianças de dois anos foi usado neste experimento. A única diferença diz respeito ao modo de apresentação dos estímulos linguísticos. Ao invés de gravados, foram produzidos diretamente pela experimentadora durante a atividade, sendo adaptados à técnica de Seleção de Imagem, como será visto a seguir.

Design: O experimento consistiu de uma fase de aprendizagem e de uma fase de teste, tal como o experimento anterior. A fase de aprendizagem transcorreu da mesma maneira. Na fase de teste, após a apresentação das imagens simultaneamente, a pesquisadora pedia à criança: "Mostra pra mim qual mepoü. O participante apontava, então, para a animação escolhida. Foi considerada a variável independente, em seus dois níveis. A variável dependente foi a taxa de escolha da imagem congruente ao estímulo linguístico.

Procedimento: Os participantes foram testados individualmente em creches, com a técnica de Seleção de Imagem. A pesquisadora comparecia à instituição em horário pré-agendado com a direção. Cada criança era convidada separadamente a assistir desenhos animados na tela de um notebook em uma sala reservada para a aplicação da tarefa. A apresentação dos vídeos foi feita de maneira muito semelhante à do experimento anteriormente descrito, ou seja, mostrava-se à criança, agora na tela de um notebook, a apresentação de slides desenvolvida para o experimento com a técnica de fixação preferencial do olhar, mantendo-se os quatro ensaios-teste. Os estímulos auditivos eram produzidos pela pesquisadora na hora da aplicação da atividade, objetivando-se uma maior interação com o participante. Além disso, na fase de teste, era pedido à criança: "Mostra para mim qual mepou/ mepa/ mepê". Desse modo, a criança apontava na tela uma das

\footnotetext{
${ }^{6}$ A mudança da técnica experimental ocorreu por questões práticas: a técnica de seleção de imagem facilitou a aplicação do experimento em creches.

${ }^{7}$ Nos experimentos 2 e 3, não tivemos acesso à idade das crianças individualmente. Porém, nos foi passada a idade da criança mais nova e da mais velha em cada turma na qual aplicamos a atividade, de modo que foi possível calcular a idade aproximada dos participantes.
} 
duas animações. As escolhas dos participantes foram anotadas por um assistente de pesquisa para posterior análise. As previsões foram as mesmas apresentadas no experimento 1, adaptadas à variável dependente taxa de escolha. Assim, se a criança fosse capaz de perceber o significado permanente da raiz verbal em diferentes ocorrências do novo verbo, a taxa de escolha seria maior, na condição mepa, para a imagem semelhante à da familiarização. Ainda, se a criança rejeitasse a forma com o não afixo (relacionada fonologicamente, mas não morfologicamente), esperava-se maior taxa de escolha para a imagem contrária à da familiarização na condição mepê.

\subsubsection{Resultados e discussão}

A taxa de escolha das animações pelas crianças em cada ensaio-teste pode ser verificada na tabela abaixo:

Tabela 5 - Número de escolhas (máx.: 16) das animações por condição - crianças de três anos de idade

\begin{tabular}{lll}
\hline TESTE & MESMA AÇÃO & AÇÃO DIFERENTE \\
\hline MEPOU & 11 & 5 \\
MEPA & 6 & 10 \\
MEPE & 7 & 9 \\
NÃO MEPOU & 9 & 7 \\
\hline
\end{tabular}

As crianças demonstraram ter conhecimento do conceito de mepar após uma curta familiarização. 68,75\% das respostas (11 de 16), quando testado o estímulo "Ele mepou", foram para mesma ação da fase de aprendizagem. Submetendo os dados a uma análise estatística (teste-t), no que se refere ao ensaio de teste "Ele mepou", temos que as escolhas pela mesma ação mostrada na fase de aprendizagem do grupo 1 (familiarizado com o peixinho passando por cima da bolha) ficaram no nível da chance (média de 0.5). Já as escolhas do grupo 2 (familiarizado com o peixinho entrando na bolha) pela mesma ação ficaram acima do nível da chance (média de 0.875 ), revelando uma diferença estatisticamente significativa entre as escolhas pela mesma ação da fase de aprendizagem e a ação diferente (ação nova) $(\mathrm{t}(7)=3.0, \mathrm{p}=0.009$ ). Quando considerados como um único grupo, a diferença na taxa de escolhas mostra-se marginalmente significativa $(\mathrm{t}(14)=1.57, \mathrm{p}=0.06)$.

No entanto, os participantes não tomaram mepa como variante de mepou, uma vez que não houve uma sistematicidade para a escolha de mepa como a mesma ação de mepou. Apenas 37,5\% das respostas (6 de 16), quando testado o estímulo "Ele mepa", foram pela mesma ação de mepou, ou seja, a animação mostrada na fase de aprendizagem. Ao ouvirem mepê, $43,75 \%$ das respostas das crianças ( 7 de 16) foram pela mesma ação e $56,25 \%$ (9 de 16) apontaram para a ação diferente da mostrada na fase de aprendizagem, sugerindo um comportamento semelhante ao de "mepa".

O comportamento das crianças diante do estímulo mepou foi ao encontro das nossas previsões. Dessa forma, os resultados sugerem a aquisição do novo verbo. No entanto, ao ouvirem mepa, as crianças apresentaram um comportamento distinto do levantado nas previsões, não evidenciando o conhecimento da variação morfológica desse verbo.

A partir dos resultados obtidos com as crianças de aproximadamente três anos de idade, decidimos verificar o comportamento de crianças de aproximadamente quatro anos diante de condições experimentais idênticas. Buscamos verificar, assim, se captaríamos evidências de habilidades de processamento morfológico (não encontradas na atividade com crianças aos três anos de idade) com um experimento idêntico, possibilitando, dessa forma, uma comparação entre os resultados. 


\subsection{Experimento 3}

\subsubsection{Método}

Participantes: 12 crianças de aproximadamente quatro anos de idade, sendo cinco meninas e sete meninos.

Material, design, procedimento e previsões foram os mesmos apresentados no Experimento 2.

\subsubsection{Resultados e discussão}

A tabela abaixo mostra o número de vezes que as crianças apontaram para a cena com a qual foram familiarizadas e para a cena nova quando ouviram cada um dos ensaios da fase de teste:

Tabela 6 - Número de escolhas (máx.: 12) das animações por teste - crianças de quatro anos de idade

\begin{tabular}{lll}
\hline TESTE & MESMA AÇÃO & AÇÃO DIFERENTE \\
\hline MEPOU & 12 & 0 \\
MEPA & 8 & 4 \\
MEPE & 9 & 3 \\
NÃO MEPOU & 8 & 4 \\
\hline
\end{tabular}

Os resultados obtidos com crianças de aproximadamente quatro anos de idade são robustos no que diz respeito à aquisição do conceito do novo verbo após uma curta fase de aprendizagem, visto que, todas as crianças (100\% dos casos), ao ouvirem “mepoü, apontaram para a cena com a qual foram familiarizadas. No que concerne ao processamento morfológico, quando era pedido às crianças para mostrarem qual dos peixinhos "mepa", a taxa de acertos foi alta: $66,7 \%$ das respostas ( 8 de 12 ) foram pela mesma ação mostrada na fase de aprendizagem, demonstrando que a maioria das crianças assumiu mepa como variação de mepou. No entanto, a taxa de escolha para a mesma ação de mepou também foi alta para o pseudoverbo adjungido a um não afixo: 75\% das crianças (9 de 12), ao ouvirem “mepêe", apontaram para a mesma ação de mepou, sugerindo que estavam tratando mepê como variação flexional desse verbo. Nesse caso, a diferença na taxa de escolhas pela ação familiar (mostrada na fase de aprendizagem) em comparação à ação nova mostrou-se estatisticamente significativa $(\mathrm{t}(10)=1.934, \mathrm{p}=0.04)$. Por fim, aos quatro anos de idade, as respostas ao estímulo “não mepou” sustentam a aquisição do novo verbo, visto que 66,7\% (8 de 12) apontaram para a ação mostrada na fase de aprendizagem como o peixinho "não conseguindo mepar".

Diante dos resultados, que sugerem uma diferença comportamental entre crianças de aproximadamente três e quatro anos de idade, conduzimos uma nova análise estatística (teste qui-quadrado), comparando o número de escolhas pela mesma ação e o número de escolhas pela ação nova em cada experimento. Os resultados apontam para uma sistematicidade na escolha das crianças mais velhas pela mesma animação mostrada na fase de aprendizagem. No experimento 3 (com crianças de quatro anos) temos uma diferença estatisticamente significativa entre a taxa de escolhas pela ação familiar e pela ação nova $(\mathrm{X}=8.6177, \mathrm{p}=$ 0.003). Por outro lado, no experimento 2 (com crianças de três anos de idade), quando os dados foram submetidos ao teste qui-quadrado, não houve resultado estatisticamente significativo $(\mathrm{X}=0,002, \mathrm{p}=0.95)$. A análise estatística ressalta, assim, uma diferença comportamental decorrente do fator idade.

\section{CONCLUSÃO}

Este estudo teve como objetivo verificar o reconhecimento, por crianças adquirindo o PB, da parte das formas verbais que veicula um significado constante. Verificamos, portanto, a aquisição de um novo verbo por crianças com idades aproximadas de dois a quatro anos adquirindo o PB, bem como o tratamento de variações flexionais desse novo verbo como palavras que compartilham um mesmo conceito base. 
Assumimos que é por meio da identificação de afixos verbais recorrentes na língua e de pistas distribucionais que a criança reconhece uma nova palavra como um verbo. O reconhecimento dos afixos verbais e a identificação da raiz como a parte do verbo que pode ocorrer com várias flexões auxiliariam na segmentação das formas verbais em raízes e afixos. Assim, a criança mapearia o conceito permanente veiculado pela raiz de um novo verbo, apesar das variações flexionais que essa palavra pode assumir dependendo da intenção de fala e do contexto sintático.

Nossos resultados sugerem que crianças adquirindo o PB acima dos dois anos (mas não abaixo dessa idade) mapeiam um novo verbo a um conceito após uma curta fase de aprendizagem. Além disso, tendem a mapear variações flexionais desse novo verbo a um mesmo conceito base. Aos três anos de idade, as crianças mapeiam o novo verbo a um mesmo significado base. Os dados não evidenciam, porém, o tratamento de variações flexionais desse novo verbo como sendo palavras relacionadas. Já os resultados das crianças de aproximadamente quatro anos de idade apontam para a aquisição do conceito de um novo verbo, bem como para o tratamento de variações flexionais desse novo verbo como tendo o mesmo significado base.

O conjunto de resultados aponta para uma capacidade progressiva da criança em mapear formas morfologicamente relacionadas a um mesmo conceito base e a reconhecer os sufixos verbais do português, a partir da segmentação interna das palavras e de pistas distribucionais. Está prevista a ampliação do número de crianças por experimento e da faixa etária investigada, testando-se, também, crianças abaixo de dois anos e acima de quatro anos. Buscamos, assim, entender melhor o processo de aquisição verbal e, em particular, da aquisição da morfologia verbal.

\section{REFERÊNCIAS}

AKTAR, N.; TOMASELLO, M. The social nature of words and word learning. In: GOLINKOFF et al. (Orgs.). Becoming a word learner: a debate on lexical acquisition. New York: Oxford Univ. Press, 2000.

BERNAL, S. et al. Syntax constrains the acquisition of verb meaning. Language learning and development, v. 3, n. 4, p. 325-341, 2007.

BORTFELD, H.; MORGAN, J.; GOLINKOFF, R.; RATHBUN, K. Mommy and me: Familiar names help launch babies into speech stream segmentation. Psychological science, v. 16, p. 298-304, 2005.

CHOMSKY, N. The Minimalist Program. Cambrigde, Mass.: The MIT Press, 1995.

. Derivation by phase. MIT Occasional Papers in Linguistics, n. 18, Cambridge, MA: MIT Working Papers in Linguistics, 1999.

. Beyond explanatory adequacy. MIT Occasional Papers in Linguistic, v. 20, 2001.

CHRISTOPHE, A.; GUASTI, T.; NESPOR, M.; DUPOUX, E.; VAN OOYEN, B. Reflections on phonological bootstrapping: its role for lexical and syntactic acquisition. Language and cognitive processes, v. 12 , n. 5/6, p. 585-612, 1997.

; MILLOTTE, S.; BERNAL, S.; LIDZ, J. Bootstrapping lexical and syntactic acquisition. Language and speech, v. 51, n. 1/2, p. 61-75, 2008.

CORRÊEA, L. M. S. O que, afinal, a criança adquire ao adquirir uma língua? A tarefa da aquisição da linguagem em três fases e o processamento de informação de interface pela criança. Letras de hoje, v. 42, n. 1, p. 7-34, 2007.

. A identificação de traços formais do léxico pela criança numa perspectiva psicolinguística. Organon, v. 23, p. 71-94, 2009.

CUTLER, A. Phonological cues to open- and closed-class words in the processing of spoken sentences. Journal of Psycholinguistic research, v. 22, n. 2, p. 109-131, 1993.

FIGUEIRA, R. A. A aquisição do paradigma verbal do português: as múltiplas direções dos erros. In: ALBANO, E.; COUDRY, M. I. H.; POSSENTI, S.; ALKMIM, T. (Orgs). Saudades da língua: a linguística e os 25 anos do Instituto de Estudos da Linguagem da UNICAMP. Campinas, SP: Mercado de Letras, 2003.

GLEITMAN, L. The Structural Sources of Verb Meanings. Language Acquisition, v. 1, n. 1, p. 3-55, 1990. 
HOLLICH, G. Supercoder: a program for coding preferential looking (Version 1.7.1). [Computer Software]. West Lafayette: Purdue University, 2008.

JUSCZYK, P. W.; HOUSTON, D. M.; NEWSOME, M. The beginnings of word segmentation in englishlearning infants. Cognitive Psychology, v. 39, p. 159-207, 1999.

LOPES, R. E. V.; SOUZA, T. T.; ZILLI, A. S. Tempo e concordância e seus efeitos na aquisição do português brasileiro. In: ENCONTRO DO CELSUL, 6., 2004, Florianópolis. Anais do... pp. 1-10, 2005.

MORGAN, J.L.; DEMUTH, K. Signal to syntax: an overview. In: . (Eds.). Signal to syntax:

Bootstrapping from speech to grammar in early acquisition. Mahwah, NJ: Lawrence Erlbaum Associates Inc., 1996. p. 1-22.

ROSA, M. C. Introdução à morfologia. 5. ed. São Paulo: Contexto, 2006.

SHI, R.; CYR, M. Processing of morphological variation in toddlers. In: K. Franich, K.M. Iserman; L.L. Keil (Eds.), BUCLD 34: Proceedings of the 34th annual Boston University conference on language development. Boston, MA: Cascadilla Press, 2010. v. 2, p. 363-374.

; MORGAN, J. L.; ALLOPENNA, P. Phonological and acoustic bases for early grammatical category assignment: a cross-linguistic perspective. Journal of Child Language, v. 25, p. 169-201, 1998.

; WERKER, J.; CUTLER, A. Recognition and representation of function words in English-learning infants. Infancy, v. 10, p. 187-198, 2006.

SODERSTROM, M. The acquisition of inflection morphology in early perceptual knowledge of syntax. Doctoral Dissertation. Johns Hopkins University, Baltimore, Maryland, 2002.

WERKER, J.; FENNELL, C. Listening to sound versus listening to words: early steps in word learning. In: HALL, G.; WAXMANN, S. (Eds.). Weaving a lexicon. Cambrigde, Mass.: The MIT Press, 2004. p. 79110.

; TEES, R. Cross-language speech perception: evidence for perceptual reorganization during the first year of life. Infant behavior and development, v. 7, p. 49-63, 1984.

et al. Infants' ability to learn phonetically similar words: effects of age and vocabulary size. Infancy, v. 3, p. $1-30,2002$.

Recebido em 12/07/2014. Aprovado em 28/09/14. 